\title{
Tunable recombinant protein expression in $E$. coli: promoter systems and genetic constraints
}

\author{
Lukas Marschall $^{1}$ P Patrick Sagmeister ${ }^{2} \cdot$ Christoph Herwig $^{1,3}$
}

Received: 18 September 2016/Revised: 26 November 2016 / Accepted: 29 November 2016 / Published online: 21 December 2016

(C) The Author(s) 2016. This article is published with open access at Springerlink.com

\begin{abstract}
Tuning of transcription is a promising strategy to overcome challenges associated with a non-suitable expression rate like outgrowth of segregants, inclusion body formation, metabolic burden and inefficient translocation. By adjusting the expression rate - even on line - to purposeful levels higher product titres and more cost-efficient production processes can be achieved by enabling culture long-term stability and constant product quality. Some tunable systems are registered for patents or already commercially available. Within this contribution, we discuss the induction mechanisms of various Escherichia coli inherent promoter systems with respect to their tunability and review studies using these systems for expression tuning. According to the current level of knowledge, some promoter systems were successfully used for expression tuning, and in some cases, analytical evidence on single-cell level is still pending. However, only a few studies using tunable strains apply a suitable process control strategy. So far, expression tuning has only gathered little attention, but we anticipate that expression tuning harbours great potential for enabling and optimizing the production of a broad spectrum of products in E. coli.
\end{abstract}

Lukas Marschall and Patrick Sagmeister contributed to this work equally.

Christoph Herwig

christoph.herwig@tuwien.ac.at

1 Institute of Chemical Engineering, Research Area Biochemical Engineering, Vienna University of Technology, Vienna, Austria

2 Exputec GmbH, Vienna, Austria

3 Christian Doppler Laboratory for Mechanistic and Physiological Methods for Improved Bioprocesses, Vienna University of Technology, Gumpendorferstrasse 1a/166-4, A-1060 Vienna, Austria
Keywords All-or-none induction · E. coli Promoter · Transcription · Tunable

\section{Introduction}

Tuning of transcription is a promising technology for efficient recombinant protein production in Escherichia coli. Many challenges like inclusion body formation (Baig et al. 2014; Hartley and Kane 1991), metabolic burden (Bentley et al. 2009; Bienick et al. 2014; Glick 1995; Mairhofer et al. 2013), inefficient translocation (Baneyx and Mujacic 2004) and outgrowth of segregants (Beisel and Afroz 2016) associated with a non-suitable expression rate can be addressed by adjusting the expression rate to purposeful levels (Marschall et al. 2015). This can either be achieved by using a low producing mutant strain or a host harbouring, a tunable promoter system, which offers the possibility to vary the protein expression on line on cellular level. In contrast to the use of various mutants with diverse expression strengths, a tunable strain opens up new possibilities. Continuous processing could benefit from the on line controllability of the transcription rate resembling an adjustment knob to manoeuvre an "out of specs" process back into the design space and enable long-term production periods (Marschall et al. 2015). A handful of contributions deals with that promising technology, two claimed-to-be tunable strains are commercially available (TunerTM, Novagen and Lemo21 DE3, New England Biolabs) (Schlegel et al. 2012; Turner et al. 2005), and one is registered for patent approval (Jay D. Keasling 2012).

Defining transcription tuning as the purposeful adjustment of the recombinant gene transcription rate on cellular level, we recently reviewed genetic and process technological aspects of transcription tuning (Marschall et al. 
2015), identified certain prerequisites for tunable promoter systems and proposed a roadmap for development of industrial tunable expression systems. In order to be tunable on a cellular level, a tunable promoter system must not exhibit all-or-none induction, i.e. the formation of subpopulations of producing and non-producing cells, but has to respond to the inducer in a dose-dependent manner (Marschall et al. 2015). Some promoter systems, which in their native form respond in an all-or-none fashion, can be rendered tunable by genetic alterations or process technological means. Therefore, the induction mechanisms and kinetics of the used promoter systems as well as process technological aspects need to be considered. Though several E. coli promoter systems have been investigated in various studies, a comprehensible review of $E$. coli promoter systems with respect to their tunability is still missing.

While our first review aimed more at process technological solutions for expression tuning and its implementation in an industrial context, within this contribution, we would like to fill the previously described gap and review induction mechanisms of common $E$. coli inherent promoter systems with respect to their tunability and discuss genetic and process technological solutions to achieve tunability for each system. A lot of different promoter systems for recombinant protein expression in E. coli are available and applied in research and industry (Balzer et al. 2013; Brautaset et al. 2009). However, within this article, we would like to focus on E. coli inherent promoter systems. In addition to that, we discuss reports that claim to apply transcription tuning and set them into context with the current knowledge on their induction mechanisms and kinetics.

\section{Promoter systems for tunable recombinant protein expression}

In the following section, promoter systems that are reported to feature tunability are reviewed. For each system, a short overview of general characteristics is given. Subsequently, its functionality is reviewed and discussed with respect to its tunability. The systems discussed in this section are outlined in Table 1.

\section{Plac system}

\section{General characteristics of the plac system}

The $\mathrm{p}_{\text {lac }}$ promoter can either be induced by its natural inducer lactose (allolactose) and by gratuitous inducers like isopropyl $\beta$-D-1-thiogalactopyranoside (IPTG) and thiomethyl- $\beta$-D-galactoside (TMG) (Herzenberg 1959). Like lactose, TMG and IPTG are both recognized by lactose permease (LacY) and can therefore enter the cell membrane either by active or diffusive transport or a combination of both (Fernández-Castané et al. 2012; Hansen et al. 1998; Maloney and Rotman 1973; Marbach and Bettenbrock 2012). The intracellular inducer concentration can also decrease in course of the process: lactose can be metabolized by E. coli using its inherent sugar uptake pathways. TMG and IPTG cannot be metabolized, but they can be acetylated by the lac operon gene lacA (thiogalactoside transacetylase) (Marbach and Bettenbrock 2012). The acetylated derivatives cannot interact with the lac repressor anymore and are consequently transported out of the cell. The route of exit is believed to be a concentration gradient (diffusive transport) (Wilson and Kashket 1969). It is believed that catabolite activator protein is essential for expression of the lac operon, but not involved in catabolite repression. The main driving force of catabolite repression in the lac operon seems to be inducer exclusion, but is still controversial in literature (Crasnier-Mednansky 2008; Görke and Stülke 2008a; Görke and Stülke 2008b).

\section{Plac system tuning on cellular level is possible using metabolisable inducers}

Several authors reported that the $\mathrm{p}_{\text {lac }}$ system using a nonmetabolisable inducer is submitted to all-or-none induction, which impedes tuning on cellular level (Afroz et al. 2014b; Narang and Pilyugin 2008; Novick and Weiner 1957; Ozbudak et al. 2004; Rao and Koirala 2014; Savageau 2011; Siegele and Hu 1997). However, recently, Afroz et al. outlined that the induction characteristics of this system are more complex: tuning on cellular level is possible using lactose as metabolisable inducer (Afroz et al. 2014b), which stands in contrast to the all-or-none response found through TMG and IPTG induction (Marbach and Bettenbrock 2012). The authors concluded that the all-or-none response is due to active transport of IPTG or TMG (Afroz et al. 2014b).

This has the practical implication that high catabolic activity paired with a low transport activity results in a graded response (lactose case), whereas a low catabolic activity paired with a high transport activity yields an all-or-none response (IPTG and TMG case) for the $\mathrm{p}_{\text {lac }}$ system (Afroz et al. 2014b).

The findings of Afroz et al. (2014b) contradict the observations made by Khlebnikov et al. (2002). Afroz et al. demonstrated a graded response of E. coli MG1655 upon induction with lactose in a range of 1 to $100 \mu \mathrm{M}$. Khlebnikov et al. (2002) observed a bistable response of E. coli D1210 upon induction with lactose up to $100 \mu \mathrm{M}$. This dissent needs to be addressed in further studies.

As regards the use of lactose as metabolisable inducer, lacZ mutant strain was reported to show all-or-none 
Table 1 Quick recap in literature reported systems with respect to tunability. "Proof of tunability" refers to whether or not tunability on cellular level was demonstrated for the respective system

\begin{tabular}{|c|c|c|c|c|c|c|}
\hline Promoter & Genotype & Add. plasmid & Inducer & $\begin{array}{l}\text { Proof of } \\
\text { tunability }\end{array}$ & Comments & Reference \\
\hline \multirow[t]{4}{*}{$\mathbf{p}_{\text {lac }}$} & Complete & - & Lactose & No & $\begin{array}{l}\text { According to lactose } \mathrm{p}_{\text {lac }} \text { induction } \\
\text { mechanistic (Afroz et al. 2014b), } \\
\text { probably tunable }\end{array}$ & (Striedner et al. 2003) \\
\hline & Complete & - & IPTG/TMG & No & $\begin{array}{l}\text { According to IPTG } p_{\text {lac }} \text { induction } \\
\text { mechanistic (Afroz et al. 2014b), } \\
\text { probably not tunable }\end{array}$ & (Striedner et al. 2003) \\
\hline & $\operatorname{lacY-}$ & - & IPTG/TMG & Yes & & Tuner $^{\mathrm{TM}}$, (Turner et al. 2005) \\
\hline & lacY-lacA- & - & IPTG/TMG & Yes & & \\
\hline \multirow[t]{4}{*}{$p_{\text {araBAD }}$} & Complete & - & $\begin{array}{l}\text { Arabinose } \\
\text { mixed feed }\end{array}$ & Yes & & (Sagmeister et al. 2013b) \\
\hline & $\begin{array}{l}\operatorname{araE-} \\
\quad \operatorname{araFGH-}\end{array}$ & $\begin{array}{l}\text { araE under } \\
\text { control of } \\
\text { different } \\
\text { promoter }\end{array}$ & Arabinose & Yes & & (Khlebnikov et al. 2002) \\
\hline & $\operatorname{araBD}-$ & - & Arabinose & No & According to arabinose $\mathrm{p}_{\text {araBAD }}$ induction & (Sommer et al. 2010) \\
\hline & $\operatorname{araBAD-}$ & - & Arabinose & No & $\begin{array}{l}\text { mechanistic (Afroz et al. 2014b), } \\
\text { probably not tunable }\end{array}$ & \\
\hline prhaBAD $_{\text {rha }}$ & Complete & pLemo & Rhamnose/IPTG & l & & (Wagner et al. 2008) \\
\hline p $_{\text {rhaT }}$ & Complete & - & Rhamnose & / & & (Giacalone et al. 2006) \\
\hline $\mathbf{p}_{\text {proU }}$ & Complete & - & $\mathrm{NaCl}$ & No & $\begin{array}{l}\text { According to } \mathrm{NaCl} \mathrm{p}_{\mathrm{rou}} \text { induction } \\
\text { mechanistic (Lucht and Bremer 1994), } \\
\text { probably tunable }\end{array}$ & (Herbst et al. 1994) \\
\hline $\mathbf{p}_{\text {prpB }}$ & Complete & - & Propionate & Yes & & (Lee and Keasling 2005) \\
\hline
\end{tabular}

behaviour when induced by lactose (Afroz et al. 2014b). Hence, for tuning on cellular level in the respective system via lactose as inducer, $\operatorname{lac}^{+} \mathrm{lac}^{+}$strains are obligatory (Fig. 1).

\section{Plac system tuning on cellular level is possible using lacY mutants}

Next to using metabolisable inducers (lactose), tuning on cellular level using the $\mathrm{p}_{\mathrm{lac}}$ system could be achieved using lac $Y$ mutant strains (lactose transport deficient strains) with gratuitous inducers (Jensen et al. 1993; Khlebnikov and Keasling 2002; Marbach and Bettenbrock 2012) (Fig. 1). Furthermore, Marbach et al. reported that LacA (thiogalactoside transacetylase) activity leads to a decrease in expression levels as the inducer concentration at single-cell level is decreasing (Marbach and Bettenbrock 2012). Therefore, while knockout of lacY is mandatory, also lacA knockout is recommended when using IPTG as non-metabolisable inducer. A similar behaviour is expected for TMG, however, to our knowledge not proven yet.

\section{Tuning of the lac operon-application in bioprocesses}

Striedner et al. reported transcription of human superoxide dismutase using T7 polymerase under control of lacUV5 in E. coli $\mathrm{K} 12$ strain HMS174(DE3) (intact lac operon) with
IPTG (Striedner et al. 2003). In fed-batch experiments with an exponential feed of substrate, IPTG was fed in accordance to the expected biomass at a constant ratio of IPTG to biomass. They were able to maintain the productivity of the culture for a longer period compared to a process with conventional one-point addition of inducer and observed a 3.5-fold increase of overall product titre. However, a proof of tuning on cellular level was not provided. Afroz et al. reported that $E$. coli strains with an intact lac operon cannot be tuned with IPTG as inducer due to the all-or-none induction phenomenon (Afroz et al. 2014b). Hence, it is to assume that inducer titration using IPTG with intact lac operon (as applied in this case) does not result in tuning on cellular level.

In the same study, Striedner et al. used the same host, vector and product, but applied lactose as inducer instead of IPTG (Striedner et al. 2003). In fed-batch experiments with an exponential feed of substrate, lactose was fed as inducer in accordance to a constant specific lactose uptake rate. They were able to maintain the productivity of the culture for a longer period compared to both a process with conventional onepoint addition of inducer and the process with IPTG inducer titration and observed twofold increase of overall product titre. In this study, an analytical proof on single-cell level was not provided, but considering the previous discussed findings of Afroz et al. (Afroz et al. 2014b), it is plausible that the increased productivities can be attributed to transcription tuning on single-cell level in this case. In contrast to the process with 


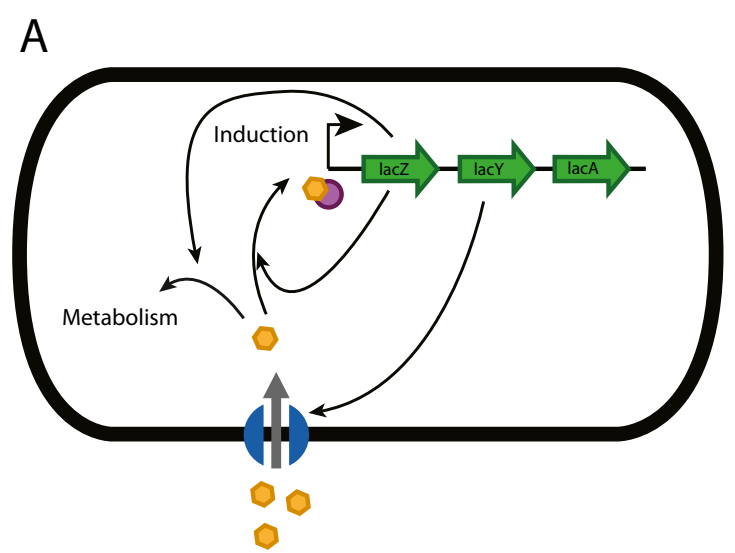

\begin{tabular}{|lll|}
\hline Lactose & (1) Active transport \\
IPTG / TMG & OD Passive transport \\
\hline
\end{tabular}

Fig. 1 Two possible ways of achieving transcription tuning with the $p_{\text {lac }}$ system are described in literature. One reported way to achieve a graded response is to use a $\mathrm{lacZ}^{+}$and $\mathrm{lacY}^{+}$strain with lactose as inducer (a). In this case, lactose induces the expression of lac $Z$ (negative feedback) and therefore turns the all-or-none response caused by induction of lacY (positive feedback) into a graded response (Afroz et al. 2014b). Another possibility to achieve a graded response is to use a $\operatorname{lac} Y$ strain with IPTG (b) (Jensen et al. 1993; Khlebnikov and Keasling 2002). As the gratuitous inducers (IPTG and TMG) are also recognized by LacY, but

IPTG, the biomass yield coefficient was constant during the whole process. This might indicate that the cells were not overburdened, since a drop in the biomass yield coefficient is reported to correlate with the metabolic load imposed on the cells (Sagmeister et al. 2012).

Several other studies used lacY deficient strains with gratuitous inducer to achieve expression tuning (Hartinger et al. 2010; Hillier et al. 2005; Turner et al. 2005). In order to increase the amount of soluble target protein, Hartinger et al. compared a variety of process conditions and host strains including BL21(DE3) Tuner ${ }^{\mathrm{TM}}$. Tuner ${ }^{\mathrm{TM}}$ is a lac $Z Y^{-}$derivative of $E$. coli BL21, which is available in various types and allows tunable transcription upon induction with IPTG. The inducer was added as one-point addition, and induction phase was maintained for $3 \mathrm{~h}$. With varying inducer concentrations, they observed a correlation between IPTG concentration and titre, but no influence on solubility of the product (Hartinger et al. 2010).

Hillier et al. developed a 300-L GMP fermentation process for liver-stage antigen 1 in BL21(DE3) TunerTM (Hillier et al. 2005). Inducer was added as one-point addition, and induction phase was maintained for $2 \mathrm{~h}$. The tunable ability of the strain was however not exploited as the culture was induced with $1 \mathrm{mM}$ IPTG, which is expected to fully induce the promoter according to other studies (Hartinger et al. 2010; Turner et al. 2005).

Turner et al. used BL21(DE3) Tuner ${ }^{\mathrm{TM}}$ to tune the expression of a target protein (cyclomaltodextrinase of thermophilic origin) with respect to solubility (Turner et al. 2005).

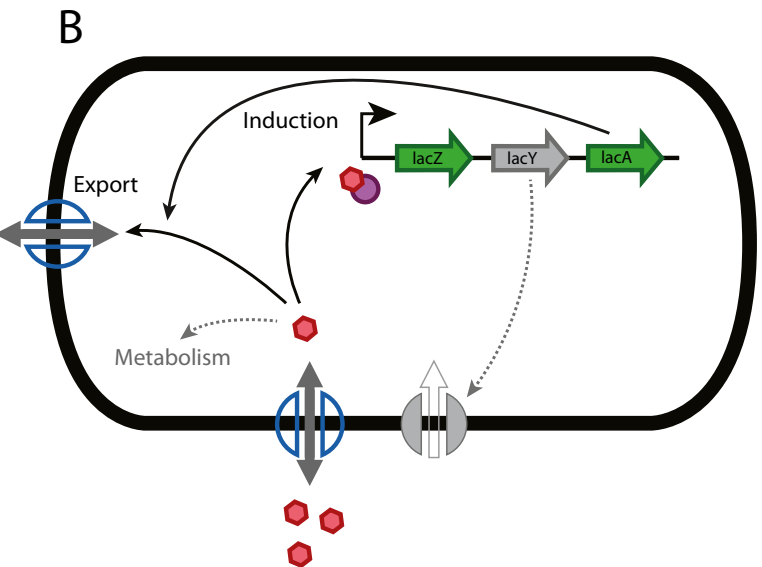

cannot be metabolized, the positive feedback needs to be interrupted by deleting lacY (Marbach and Bettenbrock 2012). The transacetylase activity of LacA modifies IPTG in a way that it loses its inducing ability and therefore leads to a decrease in single-cell expression levels by decreasing the inducer concentration (Marbach and Bettenbrock 2012). That is why using a $l a c A^{-}$mutant is recommended (not shown in this graphic). For better clarity, the role of CRP in the regulation of the lac operon is not illustrated in this graphic, but is nicely described elsewhere (Ozbudak et al. 2004)

Cultivations were performed in shake flasks. Induction with IPTG was performed as one-point addition, and induction phases were maintained for $4 \mathrm{~h}$. Inducer concentrations were varied. They observed an influence of transcription rate on the ratio of soluble protein and inclusion bodies. At subsaturating inducer concentrations, higher amounts of soluble protein and activity were detected. With increasing ITPG concentrations, the activity and the amount of soluble protein decreased, whereas the inclusion body concentration increased. These results suggest that tuning of transcription is a useful tool to suppress inclusion body formation.

\section{araBAD system}

\section{General characteristics of the araBAD system}

Another commonly used promoter is the $\mathrm{pBAD}$ promoter of the araBAD operon. The araBAD operon enables $E$. coli to take up and metabolize L-arabinose (Schleif 2000). It is induced by Larabinose. Until now, no gratuitous inducer is reported in literature to induce the wild-type promoter. The non-metabolisable Larabinose analogue D-fucose acts as inhibitor as it binds to AraC but does not induce transcription (Greenblatt and Schleif 1971; Wilcox 1974). By mutation of $\mathrm{araC}$, it is possible to render the system inducable by D-fucose (Beverin et al. 1971). L-arabinose and D-fucose are both transported into the cell by AraE and AraFGH (Daruwalla et al. 1981). The regulation of the araBAD operon is excellently described by Schleif (Schleif 
2000). It consists of two transporter genes araE and araFGH (Daruwalla et al. 1981), the genes for arabinose catabolism araBAD (Englesberg 1961), a gene of yet unknown function $\operatorname{araJ}$ (Fritz et al. 2014; Reeder and Schleif 1991) and the regulation gene araC (Saviola et al. 1998; Schleif 2010). All genes are under arabinose-inducible control of $\mathrm{AraC}$, which regulates its own expression as well. Besides the positive regulation, it also acts negatively on $\operatorname{araBAD}$ and $\operatorname{araC}$. During the absence of arabinose, AraC acts on araBAD as repressor and as activator in the presence of arabinose (Schleif 2010). It is also dependent on the activation by cAMP receptor protein, which renders the system prone to catabolite repression. In the presence of glucose or glucose-6-phosphate, the basal expression level can therefore be held at lower levels (Miyada et al. 1984). AraE and AraFGH do not act independently, and AraE is the more prevailing transporter of these two (Daruwalla et al. 1981).

Transcription kinetics for the system are reported as follows: Transcription from the $\mathrm{p}_{\mathrm{araBAD}}$ promoter is turned on 1 min after induction with arabinose (Guzman et al. 1995) and turned off in about $3 \mathrm{~min}$ after arabinose removal (Fritz et al. 2014). The fast and homogenous shut off of $p_{\text {araBAD }}$ transcription is not due to catabolism, but is believed to stand in connection with the arabinose efflux (Fritz et al. 2014).

\section{araBAD system tuning on cellular level can either be achieved by genetic engineering or process technology}

Regarding the all-or-none phenomenon, the system shows formation of subpopulations of producing and non-producing cells at low arabinose concentrations. A graded response is observed when all cells are induced at higher arabinose concentrations (Afroz et al. 2014b). Strains deficient of enzymes for arabinose catabolism are subject to all-or-none induction (Afroz et al. 2014b; Siegele and Hu 1997), and even native strains show a bistable behaviour (Fritz et al. 2014; Makela et al. 2013).

For the araBAD system, it was shown that tuning on cellular level is possible via deleting araE and $\operatorname{araFGH}$ and replacing them by araE or araFGH under the control of a different promoter (Afroz et al. 2014a; Fritz et al. 2014; Khlebnikov et al. 2000). This is possible, since the positive feedback loop is interrupted.

A graded response of the araBAD operon can also be achieved by process technological means. Using a mixed feed strategy with glucose as main substrate and arabinose as inducing substrate, we demonstrated the tunability of the araBAD operon on cellular level (Sagmeister et al. 2013b).

\section{Tuning of the araBAD operon-application in bioprocesses}

We recently showed that an E. coli $\mathrm{C} 41$ strain can metabolize $\mathrm{D}$-glucose and L-arabinose simultaneously, and that both specific uptake rates can be controlled independently in fed-batch processes, opening the way for a mixed-feed bioprocess for this systems (Sagmeister et al. 2013a). In a subsequent study, the tunability of this mixed-feed process was shown using green fluorescent protein under control of $p_{\text {araBAD }}$ as model protein in fed-batch processes (Sagmeister et al. 2013b). Flow cytometry analysis revealed that the culture was tuned on cellular level, although a small subpopulation of non-induced cells was present, but independent of the expression level applied. Afroz et al. did not observe a strictly graded response for the $p_{\text {araBAD }}$ system (2014b). Their data revealed that Larabinose-induced cells (E. coli MG165) exhibit an all-ornone response at low sugar concentrations and a graded response once all cells have been induced. This observation is in line with our findings and might explain the tunability of $p_{\text {araBAD }}$ in a mixed-feed environment as we observed an Larabinose accumulation for about 10 min upon induction, which was consumed shortly after. This short-term accumulation might lead to the induction of the entire population. We observed a linear relationship between specific arabinose uptake rate $\left(\mathrm{q}_{\mathrm{s}_{\mathrm{L}} \mathrm{L}-\text { arabinose }}\right)$ and specific productivity $\left(\mathrm{q}_{\mathrm{p}}\right)$. The specific productivity directly responded to adjustments of $\mathrm{q}_{\mathrm{s} \_ \text {_-arabinose }}$, and within specific ranges, both variables were directly proportional. Hence, an increase in $\mathrm{q}_{\mathrm{s} \text { L-arabinose }}$ resulted in an increase in $\mathrm{q}_{\mathrm{p}}$. Within this study, it was demonstrated that tunability of $\mathrm{p}_{\text {araBAD }}$ in a $E$. coli with intact arabinose operon can be achieved by a mixed-feed approach (Sagmeister et al. 2013b).

By constructing arabinose transport deficient strains (araEand $\operatorname{araFGH}$-), harbouring a plasmid with a copy of $\operatorname{araE}$ or araFGH under the control of a separate promoter, Khlebnikov et al. were able to generate a dose-dependent and uniform induction on cellular level under subsaturating arabinose concentrations (Khlebnikov et al. 2000). A second plasmid containing green fluorescent protein under the control of the paraBAD promoter allowed examination of single-cell expression levels by flow cytometry analysis. Experiments were performed on millilitre scale. Comparison of different kinds of promoters ( $\mathrm{p}_{\text {tac }}, \mathrm{p}_{\text {taclacuv5 }}$ and constitutive promoters of lactococcus lactis) and different gene dosages (low- and medium-copy number plasmid, genome integration) for araE expression yielded an influence of promoter strength on the homogeneity of induction (Khlebnikov et al. 2001; Khlebnikov et al. 2002). Strong promoters such as the IPTG inducible $\mathrm{p}_{\mathrm{tac}}$ and the constitutive promoter $\mathrm{p}_{\mathrm{cp} 18}$ resulted in a uniform induction within the culture at arabinose concentrations from 0 to $0.2 \%$ weight per volume. Using the weaker $\mathrm{p}_{\text {taclacUv5 }}$, only a part of the culture was induced at low arabinose concentrations. The culture-averaged fluorescence level increased with increasing inducer amount (Khlebnikov et al. 2002).

With their studies, Khlebnikov et al. proved that tunable transcription with $p_{\text {araBAD }}$ is possible when the genes encoding for arabinose transport are under control of a separate promoter. Exploitation of this system for development of 
a bioprocess for recombinant protein production is not yet described in literature.

\section{rhaBAD system}

\section{General characteristics of the rhaBAD system}

Other promoters used for recombinant protein production are the $p_{\text {rhaBAD }}$ and the $p_{\text {rhat }}$ promoter of the rha regulon. The rhaBAD regulon enables $E$. coli to metabolize L-rhamnose. It consists of a rhamnose transporter gene rhaT (Muiry et al. 1993; Tate et al. 1992), the genes for rhamnose catabolism rhaBAD (Egan and Schleif 1993) and the regulation genes rhaR and rhaS (Tobin and Schleif 1987; Tobin and Schleif 1990a; Tobin and Schleif 1990b; Vía et al. 1996; Wickstrum et al. 2009). The regulon is controlled by an induction cascade, which is triggered by L-rhamnose. In the presence of rhamnose, RhaR acts as inducer of rhaS, which itself induces transcription of rhaBAD and rhaT (Egan and Schleif 1993; Vía et al. 1996). Cyclic AMP receptor protein (CRP) functions as coactivator for the transcription of all three operons $r h a B A D$, rhaT and rhaS, which render the system susceptible to catabolite repression (Holcroft and Egan 2000a; Holcroft and Egan 2000b; Wickstrum et al. 2005). RhaS itself is capable of activating rhaSR transcription, but due to a lower CRP contribution, it results in a lower transcription than by activation with RhaR. Due to differences in the Shine-Dalgarno sequences, RhaS is expressed at a higher level than RhaR. It therefore leads to a kind of negative autoregulation which results in a decrease of rhaSR transcription (Wickstrum et al. 2009).

\section{Induction repression ratios in the rhaBAD system}

In a comparative study, the basal level of expression of $\mathrm{p}_{\mathrm{rhaBAD}}$ was ten times lower than $p_{\text {araBAD }}$ (Haldimann et al. 1998). Due to catabolite repression, it is possible to minimize the basal level of expression (Giacalone et al. 2006; Haldimann et al. 1998). However, on addition of rhamnose to cells growing in the presence of high glucose concentration, the induction levels are comparable to cells growing in the absence of glucose. This suggests that the system is still inducible when being catabolite repressed (Giacalone et al. 2006).

\section{rhaBAD operon-offering various tunable promoters?}

The rha regulon exhibits a strict all-or-none induction; hence, tuning on cellular level is not possible by one-point addition of inducer (Afroz et al. 2014b; Ozbudak et al. 2004; Rao and Koirala 2014). Using an expression system based on the rhaTRS locus ( $\left.\mathrm{p}_{\mathrm{rhaT}}\right)$, Giacalone et al. observed a dosedependent induction on cellular level (Giacalone et al. 2006). Wagner et al. used an expression system based on the $p_{\text {rhaBAD }}$ promoter. To the authors' knowledge so far, no studies were conducted aiming at the knockout of transport proteins to achieve tunable expression using the rhaBAD system.

\section{Tuning of the rhaBAD operon-application in bioprocesses}

Giacalone et al. investigated the tunability of TphoA (PhoA with the toxR transmembrane domain) and green fluorescent protein expression from the rhaT promoter $\left(\mathrm{p}_{\mathrm{rhaT}}\right)$. Different vectors (low-, medium- and high-copy plasmids) containing the reporter protein under control of $\mathrm{p}_{\mathrm{rhaT}}$ and the regulatory genes rhaR and rhaS were constructed and termed pRHA. $E$. coli MG1655 (with complete rhamnose pathway) was grown on millilitre scale and induced with L-rhamnose at varying concentrations. The authors observed a dependency of production level on inducer concentration and plasmid copy number. Flow cytometry analysis revealed that the cellular induction level indeed did vary with inducer concentration, but a fraction of non-induced cells remained and did increase with decreasing inducer concentrations. In our understanding, these results suggest that the culture is tuned on population level, and a fraction of the cells is tuned on cellular level. These ambivalent findings need to be addressed in further studies in order to define whether transcription tuning on cellular level is possible or not in this system.

Wagner et al. constructed a BL21(DE3) derivative strain, termed Lemo21(DE3). Using this strain, the possibility to adjust the T7RNAP levels by coexpression of T7 lysozyme under control of the prhaBAD promoter is reported (Wagner et al. 2008). This strain harbours two plasmids. One plasmid called pLemo contains the regulatory genes rhaS and rhaR and a variant of T7 lysozyme (LysY) under control of the $p_{\text {rhaBAD }}$ promoter. The second plasmid harbours the gene of interest under control of the $\mathrm{p}_{\mathrm{T} 7}$ promoter. The actual tuning is performed with the prhaBAD promoter and rhamnose as inducer. The resulting T7 lysozyme concentrations reduce the amount of T7RNAP and consequently the expression level of the target protein under control of $\mathrm{p}_{\mathrm{T} 7}$. This system was used for membrane protein production (Schlegel et al. 2012; Wagner et al. 2008) and recombinant protein production in the periplasm of E. coli (Schlegel et al. 2013). In shake flasks, Schlegel et al. investigated the influence of different rhamnose concentrations on culture homogeneity after $8 \mathrm{~h}$ of induction with ITPG (Schlegel et al. 2012). They observed subpopulations of induced and non-induced cells at $0 \mu \mathrm{M}$ rhamnose, when lysozyme expression was not induced. At increasing rhamnose concentrations, they observed a decrease of the non-induced fraction. Until at a certain rhamnose concentration, a uniform culture was attained. The authors attributed the non-induced fraction of the culture to outgrowth of segregants. Using the Lemo21(DE3) strain, the authors were able to identify the optimal conditions for membrane protein 
expression and therefore to achieve higher titres of correctly folded product and a more stable production period (Schlegel et al. 2012).

Since two different promoter systems ( $\mathrm{p}_{\text {lacUV5 }}$ and $\mathrm{p}_{\mathrm{rhaBAD}}$ ) are used, both have to be considered as possible causes of nonuniformity across the culture. For this reason, the system is highly complex with respect to tunability on cellular level, especially considering the findings of Afroz et al. that uniform transcription with IPTG is only possible in lacY deficient strains, and that the rhamnose utilization pathway typically responds in a strictly all-or-none fashion (Afroz et al. 2014b).

\section{proU operon}

\section{General characteristics of the proU operon}

The osmoregulated proU operon is one of three proline transport systems in E. coli providing the cell with the ability to respond to changes in osmolarity in its environment (osmotic stress). The system was reviewed by Lucht et al. (Lucht and Bremer 1994). The operon encodes three proteins: ProV (May et al. 1989), ProW and ProX (Breed et al. 2001) which regulate the transport of glycine-betaine and other osmoprotectants into the cytoplasm at high osmolarity (Gowrishankar 1985; Stirling et al. 1989). To sustain the inner cell pressure (turgor), E. coli can import $\mathrm{K}^{+}$ions via several $\mathrm{K}^{+}$transport systems as a response to a change of osmolarity in its environment (Booth 1990; Epstein 1986; Sutherland et al. 1986). The import of $\mathrm{K}^{+}$ is accompanied by production of glutamate as counter ion (Measures 1975). At higher osmolarities, the cell replaces $\mathrm{K}^{+}$ions by compounds that do not disturb metabolic activities, so called compatible solutes or osmoprotectants (Booth 1990; Epstein 1986; Sutherland et al. 1986). Induction of proU is assumed to be a mixture of elevated potassium-glutamate levels (Leirmo et al. 1987; Lucht and Bremer 1994), changes in DNA super coiling (Higgins et al. 1988; Lucht and Bremer 1994) and a repression mechanism, that only function at low osmolarities (Lucht and Bremer 1994). Transcription cannot be induced at limiting $\mathrm{K}^{+}$concentration in the medium (Sutherland et al. 1986).

\section{proU operon-promising candidate for tunable recombinant protein expression}

The system is not responsible for the import of its inducer. According to the conclusions of Afroz for other systems, it is therefore not expected to show all-or-none behaviour (Afroz et al. 2014b; Rao and Koirala 2014). It directly responds to changes in osmolarity and expression is maintained as long as the osmotic stress exists (Herbst et al. 1994; Lucht and Bremer 1994; Walawalkar et al. 2013).
Tuning of the proU operon—application in bioprocesses

Herbst et al. constructed a set of expression vectors (termed pOSEX) containing proV and the target genes under control of the $p_{\text {prou }}$ promoter (Herbst et al. 1994). With these pOSEX vectors, the expression of $\beta$-galactosidase (LacZ) and a carboxyltransferase (GcdA in E. coli MKH13 [ $\triangle$ putPA101, $\triangle p r o P 2, \Delta p r o U 608]$, a derivative of $E$. coli $\mathrm{K}-12$, was studied. Studies were performed on millilitre scale with varying $\mathrm{NaCl}$ concentrations. By SDS-PAGE analysis, the authors observed a correlation of target protein concentration and osmolarity of the growth medium. Higher osmolarities resulted in higher target protein concentrations. To be able to attribute these findings to transcription tuning on cellular level, culture uniformity (Afroz et al. 2014b; Rao and Koirala 2014) needs to be addressed by single-cell analytics in further studies. Whether or not the impact of osmotic stress on overall metabolism limits the applicability of the system needs to be investigated (Cheung et al. 2009; Roth et al. 1985; Walawalkar et al. 2013; Weber et al. 2006). Future investigations will also have to consider the impact of osmotic stress on overall metabolism and cell growth (Cheung et al. 2009; Roth et al. 1985; Walawalkar et al. 2013; Weber et al. 2006).

\section{pprpB}

The prp regulon was first described and studied for Salmonella typhimurium (Hammelman et al. 1996). A closely related operon was found in E. coli with a high identity by genomic sequencing (Blattner 1997) and radioactive labelling experiments (Textor et al. 1997). The tunability of the system was investigated in $E$. coli (Lee and Keasling 2005). The regulon enables E. coli to metabolize propionate and is induced in the presence of propionate. The regulon was intensively investigated by the group of Escalante-Semerena (Grimek et al. 2003; Hammelman et al. 1996; Horswill and Escalante-Semerena 1997; Horswill and Escalante-Semerena 1999a; Horswill and Escalante-Semerena 1999b; Horswill and Escalante-Semerena 2001; Palacios 2004; Palacios and Escalante-Semerena 2000; Tsang et al. 1998). It consists of the two operons, prpR and prpBCDE (Horswill and Escalante-Semerena 1997). Under the control of its own promoter $p_{\text {prpR }}$, the prpR operon encodes the transcriptional activator for pprpB of the sigma-54 family, which is essential for $\mathrm{p}_{\mathrm{prpB}}$ transcription (Horswill and Escalante-Semerena 1997; Palacios and Escalante-Semerena 2000). The $\mathrm{p}_{\mathrm{prpR}}$ promoter is not dependent on propionate but is activated by cAMP receptor protein and therefore believed to be solely controlled by catabolite repression (Lee et al. 2005). PrpBCDE encodes most of the enzymes of the 2-methylcitric acid cycle for oxidation of propionate to pyruvate (Brock et al. 2001; Brock et al. 2002; Grimek et al. 2003; Horswill and Escalante-Semerena 1999b; Horswill and Escalante-Semerena 2001; Palacios 2004). The single steps of the cycle are well described by Brock et al. (Brock et al. 2002). 
$\mathrm{P}_{\mathrm{prpB}}$ is not directly addressed by propionate. Propionate is converted to 2-methylcitrate (2-MC) in two consequent steps by PrpE and PrpC (Tsang et al. 1998). In the presence of 2MC, PrpR initiates transcription of prpBCDE (Palacios 2004; Palacios and Escalante-Semerena 2000). Besides of PrpR and its coactivator, the sigma-54 transcription factor and the integration host factor (IHF) are needed for prpBCDE transcription (Palacios and Escalante-Semerena 2000). The p prpB promoter itself is directly dependent on the activation by CRP. This renders the system prone to catabolite repression (Lee et al. 2005). As propionate is only the precursor of the actual inducer (2-MC), the system could be induced by endogenous metabolic pathways leading to propionate and propionylCoA.One such pathway is responsible for the conversion of succinate to propionate (Haller et al. 2000; Lee and Keasling 2005). By taking a look at the net reaction equation of this pathway (propanoyl-CoA + succinate $\leftrightarrow$ propanoate + succinyl-CoA) (Keseler et al. 2012), we conclude that no precursor for $\mathrm{p}_{\mathrm{prpB}}$ induction can synthesized de novo, at least by this pathway. However, possible alternative routes have to be considered. The cell wall is permeable for propionate (Salmond et al. 1984), and no other active import system has been reported to exist in E. coli up to now. Intracellular inducer concentration can decrease in course of the process due to metabolization of propionate and dilution due to cell growth.

\section{prpBCDE operon-tuning on cellular level is possible}

Lee et al. observed a graded induction on cellular level (Lee and Keasling 2005) in response to the extracellular propionate concentration. With no traits of autocatalytic functionality within its genome (Carrier and Keasling 1999; Rao and Koirala 2014), the prpBCDE operon is a promising tunable system. However, culture uniformity still needs to be proven by single-cell analytics.

\section{prpBCDE operon-increasing strength}

By using PrpR and $\mathrm{p}_{\mathrm{prpB}}$ of $S$. typhimurium in E. coli, the expression strength was increased in contrast to the $E$. coli inherent analogues (Lee and Keasling 2006a; Lee and Keasling 2008). A threefold higher green fluorescent protein production was observed. However, this increase came along with an increase in basal expression levels (Lee and Keasling 2006a).

\section{Tuning of the prpBCDE operon-application in bioprocesses}

Lee et al. constructed several vectors containing $\operatorname{prp} R$ (activator protein for $\mathrm{p}_{\mathrm{prpB}}$ ) and the target gene under control of the prpBCDE promoter ( $\mathrm{p}_{\mathrm{prpB}}$ ), termed pPro (Lee and Keasling 2005). E. coli DH10B with pPro vectors harbouring green fluorescent protein as marker protein was grown in millilitre scale. Cultures were induced by one-point addition of propionate at varying propionate concentrations. Culture uniformity was verified by flow cytometry measurements 2 and $6 \mathrm{~h}$ after induction. The study revealed that the culture was induced uniformly, and that the GFP expression level is a function of the propionate concentration. In a consequent study, Lee et al. investigated pPro vectors containing $\operatorname{prp} R$ and the prpBCDE promoter from S. typhimurium (Lee and Keasling 2006a; Lee and Keasling 2006b). Comparison with the E. coli based pPro vectors revealed a threefold higher GFP expression when using the Salmonella-based pPro system. As a second step, the tunability on transcriptional level of the Salmonella-based pPro system was confirmed by expressing two plant genes encoding coclaurine $N$-methyltransferase (CMT) and norcoclaurine synthase (NCS) in shake flasks (Lee and Keasling 2008). In 2012, the pPro system was registered for patent approval (Jay D. Keasling 2012).

\section{Conclusions and outlook}

Within this contribution, we provide a comprehensive overview on promoter systems that were used to apply expression tuning with $E$. coli and discuss promising candidates. To purposefully apply these systems for the benefits of (1) higher overall productivities, (2) debottlenecking of transport pathways and (3) avoiding protein aggregation, it is necessary to consider promoter system specific constraints.

So far, most of the studies dealing with tuning are proof-ofconcept studies, performed in millilitre to shake flask scale with one-point addition of inducer, but offer the necessary verification on single-cell level (Lee and Keasling 2005; Schlegel et al. 2012). In some studies, tunable systems were applied for process optimization of recombinant protein production (Hartinger et al. 2010; Turner et al. 2005) or even large scale production (Hillier et al. 2005).

However, only a few studies using tunable strains apply a suitable process control strategy (i.e. induction strategy) (Sagmeister et al. 2013b; Striedner et al. 2010). As discussed elsewhere, one-point addition of inducer is not suited when applying transcription tuning (Marschall et al. 2015). Yet, it is the most common induction method in the reviewed studies (Giacalone et al. 2006; Hartinger et al. 2010; Herbst et al. 1994; Hillier et al. 2005; Lee and Keasling 2008; Turner et al. 2005).

Some promoter systems were reported to offer tunability (Giacalone et al. 2006; Schlegel et al. 2012), which contradicts the strictly all-or-none response observed by Afroz et al. (Afroz et al. 2014b). These ambivalent findings need to be addressed in further studies. Another promising promoter system was identified, possibly enabling transcription tuning by adjustment of the media salt concentration, but needs further investigation. 
A lot of issues concerning transcription tuning have been addressed by the reviewed studies. However, some open questions still remain:

- Contradicting findings for already claimed-to-be tunable systems need to be investigated and clarified.

- Verification of culture homogeneity was not always supplied.

- Application of suitable process control strategies is mandatory in order to proof long-term stability of cell growth and recombinant protein production.

- The reviewed promoter systems only represent a small part of available promoter systems for $E$. coli, but to our knowledge, they are the ones that were applied for expression tuning so far. Therefore, a lot of other promoter systems, promising as well with respect to tunability, are still waiting to be explored (Balzer et al. 2013).

- Scale-up-related issues of tunable systems have not been investigated so far. In order to apply transcription tuning in industrial processes, the influence of substrate and inducer gradients on the tunability needs to be addressed, especially when following a mixedfeed approach.

Keeping these points in mind, it will be possible to control transcription on single-cell level and thus to an increase in productivity and product quality.

We suggest focusing on promoter systems using inducers that only act on the promoter controlling the desired recombinant genes, in future studies. Relying on inducers that also act on other parts of the cells metabolism, one might unintentionally not only induce the promoter of interest but also turn other adjusting screws that negatively influence recombinant protein expression.

To put it in a nutshell, we believe that expression tuning is a promising tool for industrial application by enabling culture long-term stability and constant product quality and thus ultimately resulting in higher product titres and more cost-efficient production processes.

Acknowledgments Open access funding provided by TU Wien (TUW).

Compliance with ethical standards This article does not contain any studies with human participants or animals performed by any of the authors.

Conflict of interest The authors declare that they have no conflict of interest.

Open Access This article is distributed under the terms of the Creative Commons Attribution 4.0 International License (http://creativecommons.org/ licenses/by/4.0/), which permits unrestricted use, distribution, and reproduction in any medium, provided you give appropriate credit to the original author(s) and the source, provide a link to the Creative Commons license, and indicate if changes were made.

\section{References}

Afroz T, Biliouris K, Boykin KE, Kaznessis Y, Beisel CL (2014a) Tradeoffs in engineering sugar utilization pathways for titratable control. ACS Synth Biol 4(2):141-149. doi:10.1021/sb400162z

Afroz T, Biliouris K, Kaznessis Y, Beisel CL (2014b) Bacterial sugar utilization gives rise to distinct single-cell behaviours. Mol Microbiol 93(6):1093-1103. doi:10.1111/mmi.12695

Baig F, Fernando LP, Salazar MA, Powell RR, Bruce TF, Harcum SW (2014) Dynamic transcriptional response of Escherichia coli to inclusion body formation. Biotechnol Bioeng 111(5):980-999. doi:10.1002/bit.25169

Balzer S, Kucharova V, Megerle J, Lale R, Brautaset T, Valla S (2013) A comparative analysis of the properties of regulated promoter systems commonly used for recombinant gene expression in Escherichia coli. Microb Cell Factories 12(26). doi:10.1186/14752859-12-26

Baneyx F, Mujacic M (2004) Recombinant protein folding and misfolding in Escherichia coli. Nat Biotechnol 22(11):1399-1408. doi:10.1038/nbt1029

Beisel CL, Afroz T (2016) Rethinking the hierarchy of sugar utilization in bacteria. J Bacteriol 198(3):374-376. doi:10.1128/JB.0089015

Bentley WE, Mirjalili N, Andersen DC, Davis RH, Kompala DS, Bentley WE (2009) Plasmid-encoded protein: the principal factor in the "metabolic burden" associated with recombinant bacteria. Biotechnol Bioeng 102(5):1283-1297. doi:10.1002/bit.22292

Beverin S, Sheppard DE, Park SS (1971) D-fucose as a gratuitous inducer of the L-arabinose operon in strains of Escherichia coli B-r mutant in gene araC. J Bacteriol 107(1):79-86

Bienick MS, Young KW, Klesmith JR, Detwiler EE, Tomek KJ, Whitehead TA, Fong SS (2014) The interrelationship between promoter strength, gene expression, and growth rate. PLoS One 9(10): e109105. doi:10.1371/journal.pone.0109105

Blattner FR (1997) The complete genome sequence of Escherichia coli K-12. Science 277(5331):1453-1462. doi:10.1126/science.277.5331.1453

Booth I (1990) Enteric bacteria and osmotic stress: intracellular potassium glutamate as a secondary signal of osmotic stress? FEMS Microbiol Lett 75(2-3):239-246. doi:10.1016/0378-1097(90)90534-w

Brautaset T, Lale R, Valla S (2009) Positively regulated bacterial expression systems. Microb Biotechnol 2(1):15-30. doi:10.1111/j.17517915.2008.00048.x

Breed J, Kneip S, Gade J, Welte W, Bremer E (2001) Purification, crystallization and preliminary crystallographic analysis of the periplasmic binding protein ProX from Escherichia coli. Acta Crystallogr D Biol Crystallogr 57(3):448-450. doi:10.1107/s0907444901000397

Brock M, Darley D, Textor S, Buckel W (2001) 2-Methylisocitrate lyases from the bacterium Escherichia coli and the filamentous fungus Aspergillus nidulans: characterization and comparison of both enzymes. Eur J Biochem 268(12):3577-3586

Brock M, Maerker C, Schütz A, Völker U, Buckel W (2002) Oxidation of propionate to pyruvate in Escherichia coli. Eur J Biochem 269(24): 6184-6194. doi:10.1046/j.1432-1033.2002.03336.x

Carrier TA, Keasling JD (1999) Investigating autocatalytic gene expression systems through mechanistic modeling. J Theor Biol 201(1): 25-36. doi:10.1006/jtbi.1999.1010

Cheung C, Lee J, Lee J, Shevchuk O (2009) The effect of ionic $(\mathrm{NaCl})$ and non-ionic (sucrose) osmotic stress on the expression of $\beta$-galactosidase in wild type E. coli BW25993 and in the isogenic BW25993 $\Delta$ lacI mutant. J Exp Microbiol Immunol (13): $1-6$

Crasnier-Mednansky M (2008) Is there any role for cAMP-CRP in carbon catabolite repression of the Escherichia coli lac operon? Nat Rev Microbiol 6(12):954. doi:10.1038/nrmicro1932-c1 
Daruwalla KR, Paxton AT, Henderson PJ (1981) Energization of the transport systems for arabinose and comparison with galactose transport in Escherichia coli. Biochem J 200(3):611-627

Egan SM, Schleif RF (1993) A regulatory cascade in the induction of rhaBAD. J Mol Biol 234(1):87-98. doi:10.1006/jmbi.1993.1565

Englesberg E (1961) Enzymatic characterization of 17 L-arabinose negative mutants of Escherichia coli. J Bacteriol 81:996-1006

Epstein W (1986) Osmoregulation by potassium transport in Escherichia coli. FEMS Microbiol Lett 39(1-2):73-78. doi:10.1111/j.15746968.1986.tb01845.x

Fernández-Castané A, Vine CE, Caminal G, López-Santín J (2012) Evidencing the role of lactose permease in IPTG uptake by Escherichia coli in fed-batch high cell density cultures. J Biotechnol 157(3):391-398. doi:10.1016/j.jbiotec.2011.12.007

Fritz G, Megerle JA, Westermayer SA, Brick D, Heermann R, Jung K, Rädler JO, Gerland U, Herman C (2014) Single cell kinetics of phenotypic switching in the arabinose utilization system of $E$. coli. PLoS One 9(2):e89532 doi:10.1371/journal.pone.0089532

Giacalone M, Gentile A, Lovitt B, Berkley N, Gunderson C, Surber M (2006) Toxic protein expression in Escherichia coli using a rhamnose-based tightly regulated and tunable promoter system. BioTechniques 40(3):355-364. doi:10.2144/000112112

Glick BR (1995) Metabolic load and heterologous gene expression. Biotechnol Adv 13(2):247-261. doi:10.1016/0734-9750 (95)00004-a

Görke B, Stülke J (2008a) Carbon catabolite repression in bacteria: many ways to make the most out of nutrients. Nat Rev Microbiol 6(8): 613-624. doi:10.1038/nrmicro1932

Görke B, Stülke J (2008b) Is there any role for cAMP-CRP in carbon catabolite repression of the Escherichia coli lac operon? Reply from Görke and Stülke. Nat Rev Microbiol 6(12):954. doi:10.1038/nrmicro1932-c2

Gowrishankar J (1985) Identification of osmoresponsive genes in Escherichia coli: evidence for participation of potassium and proline transport systems in osmoregulation. J Bacteriol 164(1):434-445

Greenblatt J, Schleif R (1971) Arabinose C protein: regulation of the arabinose operon in vitro. Nat New Biol 233(40):166-170. doi:10.1038/newbio233166a0

Grimek TL, Holden H, Rayment I, Escalante-Semerena JC (2003) Residues C123 and D58 of the 2-methylisocitrate lyase (PrpB) enzyme of Salmonella enterica are essential for catalysis. J Bacteriol 185(16):4837-4843. doi:10.1128/jb.185.16.4837-4843.2003

Guzman LM, Belin D, Carson MJ, Beckwith J (1995) Tight regulation, modulation, and high-level expression by vectors containing the arabinose PBAD promoter. J Bacteriol 177(14):4121-4130

Haldimann A, Daniels LL, Wanner BL (1998) Use of new methods for construction of tightly regulated arabinose and rhamnose promoter fusions in studies of the Escherichia coli phosphate regulon. J Bacteriol 180(5):1277-1286

Haller T, Buckel T, Rétey J, Gerlt JA (2000) Discovering new enzymes and metabolic pathways: conversion of succinate to propionate by Escherichia coli. Biochemistry 39(16):4622-4629. doi:10.1021/bi992888d

Hammelman TA, O'Toole GA, Trzebiatowski JR, Tsang AW, Rank D, Escalante-Semerena JC (1996) Identification of a new prp locus required for propionate catabolism in Salmonella typhimurium LT2. FEMS Microbiol Lett 137(2-3):233-239

Hansen LH, Knudsen S, Sørensen SJ (1998) The effect of the lacY gene on the induction of IPTG inducible promoters, studied in Escherichia coli and Pseudomonas fluorescens. Curr Microbiol 36(6):341-347

Hartinger D, Heinl S, Schwartz H, Grabherr R, Schatzmayr G, Haltrich D, Moll W-D (2010) Enhancement of solubility in Escherichia coli and purification of an aminotransferase from Sphingopyxis sp. MTA144 for deamination of hydrolyzed fumonisin B1. Microb Cell Factories 9(1):62. doi:10.1186/1475-2859-9-62
Hartley DL, Kane JF (1991) Properties of inclusion bodies from recombinant Escherichia coli. Bioprocess Technol (Bioprocess technology) $16: 24$

Herbst B, Kneip S, Bremer E (1994) pOSEX: vectors for osmotically controlled and finely tuned gene expression in Escherichia coli. Gene 151(8):137-142. doi:10.1016/0378-1119(94)90644-0

Herzenberg LA (1959) Studies on the induction of $\beta$-galactosidase in a cryptic strain of Escherichia coli. Biochim Biophys Acta 31(2):525538. doi:10.1016/0006-3002(59)90029-0

Higgins CF, Dorman CJ, Stirling DA, Waddell L, Booth IR, May G, Bremer E (1988) A physiological role for DNA supercoiling in the osmotic regulation of gene expression in S. typhimurium and E. coli. Cell 52(4):569-584

Hillier CJ, Ware LA, Barbosa A, Angov E, Lyon JA, Heppner DG, Lanar DE (2005) Process development and analysis of liver-stage antigen 1, a preerythrocyte-stage protein-based vaccine for Plasmodium falciparum. Infect Immun 73(4):2109-2115. doi:10.1128/iai.73.4.2109-2115.2005

Holcroft CC, Egan SM (2000a) Interdependence of activation at rhaSR by cyclic AMP receptor protein, the RNA polymerase alpha subunit C-terminal domain, and RhaR. J Bacteriol 182(23):6774-6782. doi:10.1128/jb.182.23.6774-6782.2000

Holcroft CC, Egan SM (2000b) Roles of cyclic AMP receptor protein and the carboxyl-terminal domain of the alpha subunit in transcription activation of the Escherichia coli rhaBAD operon. J Bacteriol 182(12):3529-3535. doi:10.1128/jb.182.12.3529-3535.2000

Horswill AR, Escalante-Semerena JC (1997) Propionate catabolism in Salmonella typhimurium LT2: two divergently transcribed units comprise the prp locus at 8.5 centisomes, prpR encodes a member of the sigma-54 family of activators, and the prpBCDE genes constitute an operon. J Bacteriol 179(3):928-940

Horswill AR, Escalante-Semerena JC (1999a) The prpE gene of Salmonella typhimurium LT2 encodes propionyl-CoA synthetase. Microbiology 145(Pt 6):1381-1388

Horswill AR, Escalante-Semerena JC (1999b) Salmonella typhimurium LT2 catabolizes propionate via the 2-methylcitric acid cycle. J Bacteriol 181(18):5615-5623

Horswill AR, Escalante-Semerena JC (2001) In vitro conversion of propionate to pyruvate by Salmonella enterica enzymes: 2methylcitrate dehydratase (PrpD) and aconitase enzymes catalyze the conversion of 2-methylcitrate to 2-methylisocitrate. Biochemistry 40(15):4703-4713. doi:10.1021/bi015503b

Jay D, Keasling SKL (2012) Inducible expression vectors and methods of use thereof. 2006

Jensen PR, Westerhoff HV, Michelsen O (1993) The use of lac-type promoters in control analysis. Eur J Biochem 211(1-2):181-191

Keseler IM, Mackie A, Peralta-Gil M, Santos-Zavaleta A, Gama-Castro S, Bonavides-Martinez C, Fulcher C, Huerta AM, Kothari A, Krummenacker M, Latendresse M, Muniz-Rascado L, Ong Q, Paley S, Schroder I, Shearer AG, Subhraveti P, Travers M, Weerasinghe D, Weiss V, Collado-Vides J, Gunsalus RP, Paulsen I, Karp PD (2012) EcoCyc: fusing model organism databases with systems biology. Nucleic Acids Res 41(D1):D605-D612. doi:10.1093/nar/gks1027

Khlebnikov A, Datsenko KA, Skaug T, Wanner BL, Keasling JD (2001) Homogeneous expression of the $\mathrm{P}(\mathrm{BAD})$ promoter in Escherichia coli by constitutive expression of the low-affinity high-capacity AraE transporter. Microbiology 147(Pt 12):3241-3247

Khlebnikov A, Keasling JD (2002) Effect of lacY expression on homogeneity of induction from the $\mathrm{P}(\mathrm{tac})$ and $\mathrm{P}(\mathrm{trc})$ promoters by natural and synthetic inducers. Biotechnol Prog 18(3):672-674. doi:10.1021/bp010141k

Khlebnikov A, Risa O, Skaug T, Carrier TA, Keasling JD (2000) Regulatable arabinose-inducible gene expression system with consistent control in all cells of a culture. J Bacteriol 182(24):70297034. doi:10.1128/jb.182.24.7029-7034.2000 
Khlebnikov A, Skaug T, Keasling JD (2002) Modulation of gene expression from the arabinose-inducible araBAD promoter. $\mathrm{J}$ Ind Microbiol Biotechnol 29(1):34-37. doi:10.1038/sj.jim.7000259

Lee SK, Keasling JD (2005) A propionate-inducible expression system for enteric bacteria. Appl Environ Microbiol 71(11):6856-6862. doi:10.1128/aem.71.11.6856-6862.2005

Lee SK, Keasling JD (2006a) Propionate-regulated high-yield protein production in Escherichia coli. Biotechnol Bioeng 93(5):912-918. doi:10.1002/bit.20784

Lee SK, Keasling JD (2006b) A salmonella-based, propionate-inducible, expression system for Salmonella enterica. Gene 377:6-11. doi:10.1016/j.gene.2006.02.013

Lee SK, Keasling JD (2008) Heterologous protein production in Escherichia coli using the propionate-inducible pPro system by conventional and auto-induction methods. Protein Expr Purif 61(2): 197-203. doi:10.1016/j.pep.2008.06.008

Lee SK, Newman JD, Keasling JD (2005) Catabolite repression of the propionate catabolic genes in Escherichia coli and Salmonella enterica: evidence for involvement of the cyclic AMP receptor protein. J Bacteriol 187(8):2793-2800. doi:10.1128/jb.187.8.2793-2800.2005

Leirmo S, Harrison C, Cayley DS, Burgess RR, Record MT (1987) Replacement of potassium chloride by potassium glutamate dramatically enhances protein-DNA interactions in vitro. Biochemistry 26(8):2095-2101. doi:10.1021/bi00382a006

Lucht JM, Bremer E (1994) Adaptation of Escherichia coli to high osmolarity environments: osmoregulation of the high-affinity glycine betaine transport system proU. FEMS Microbiol Rev 14(1):3-20

Mairhofer J, Scharl T, Marisch K, Cserjan-Puschmann M, Striedner G (2013) Comparative transcription profiling and in-depth characterization of plasmid-based and plasmid-free Escherichia coli expression systems under production conditions. Appl Environ Microbiol 79(12):3802-3812. doi:10.1128/aem.00365-13

Makela J, Kandhavelu M, Oliveira SMD, Chandraseelan JG, LloydPrice J, Peltonen J, Yli-Harja O, Ribeiro AS (2013) In vivo single-molecule kinetics of activation and subsequent activity of the arabinose promoter. Nucleic Acids Res 41(13):6544-6552. doi:10.1093/nar/gkt350

Maloney PC, Rotman B (1973) Distribution of suboptimally induced $\beta$ d-galactosidase in Escherichia coli. J Mol Biol 73(1):77-91. doi:10.1016/0022-2836(73)90160-5

Marbach A, Bettenbrock K (2012) Lac operon induction in Escherichia coli: systematic comparison of IPTG and TMG induction and influence of the transacetylase LacA. J Biotechnol 157(1):82-88. doi:10.1016/j.jbiotec.2011.10.009

Marschall L, Sagmeister P, Herwig C (2015) Tunable recombinant protein expression in E. coli: enabler for continuous processing? Appl Microbiol Biotechnol 100(13):5719-5728

May G, Faatz E, Lucht JM, Haardt M, Bolliger M, Bremer E (1989) Characterization of the osmoregulated Escherichia coli proU promoter and identification of ProV as a membrane-associated protein. Mol Microbiol 3(11):1521-1531. doi:10.1111/j.1365-2958.1989. tb00138.x

Measures JC (1975) Role of amino acids in osmoregulation of non-halophilic bacteria. Nature 257(5525):398-400. doi: $10.1038 / 257398 \mathrm{a} 0$

Miyada CG, Stoltzfus L, Wilcox G (1984) Regulation of the araC gene of Escherichia coli: catabolite repression, autoregulation, and effect on araBAD expression. Proc Natl Acad Sci U S A 81(13):4120-4124

Muiry JA, Gunn TC, McDonald TP, Bradley SA, Tate CG, Henderson PJ (1993) Proton-linked L-rhamnose transport, and its comparison with L-fucose transport in enterobacteriaceae. Biochem J 290(Pt 3):833842

Narang A, Pilyugin SS (2008) Bistability of the lac operon during growth of Escherichia coli on lactose and lactose + glucose. Bull Math Biol 70(4):1032-1064. doi:10.1007/s11538-007-9289-7
Novick A, Weiner M (1957) Enzyme induction as all-or-none phenomenon. Proc Natl Acad Sci USA (43):553-566

Ozbudak EM, Thattai M, Lim HN, Shraiman BI, van Oudenaarden A (2004) Multistability in the lactose utilization network of Escherichia coli. Nature 427(6976):737-740. doi:10.1038/nature02298

Palacios S (2004) 2-methylcitrate-dependent activation of the propionate catabolic operon (prpBCDE) of Salmonella enterica by the PrpR protein. Microbiology 150(11):3877-3887. doi:10.1099/mic.0.27299-0

Palacios S, Escalante-Semerena JC (2000) prpR, ntrA, and ihf functions are required for expression of the prpBCDE operon, encoding enzymes that catabolize propionate in Salmonella enterica Serovar Typhimurium LT2. J Bacteriol 182(4):905-910. doi:10.1128/jb.182.4.905-910.2000

Rao CV, Koirala S (2014) Black and white with some shades of grey: the diverse responses of inducible metabolic pathways in Escherichia coli. Mol Microbiol. doi:10.1111/mmi.12734

Reeder T, Schleif R (1991) Mapping, sequence, and apparent lack of function of araJ, a gene of the Escherichia coli arabinose regulon. J Bacteriol 173(24):7765-7771

Roth WG, Leckie MP, Dietzler DN (1985) Osmotic stress drastically inhibits active transport of carbohydrates by Escherichia coli. Biochem Biophys Res Commun 126(1):434 441. doi:10.1016/0006-291x(85)90624-2

Sagmeister P, Kment M, Wechselberger P, Meitz A, Langemann T, Herwig C (2013a) Soft-sensor assisted dynamic investigation of mixed feed bioprocesses. Process Biochem 48(12):1839-1847. doi:10.1016/j.procbio.2013.09.018

Sagmeister P, Schimek C, Meitz A, Herwig C, Spadiut O (2013b) Tunable recombinant protein expression with $E$. coli in a mixed-feed environment. Appl Microbiol Biotechnol. doi:10.1007/s00253-013-5445-1

Sagmeister P, Wechselberger P, Herwig C (2012) Information processing: rate-based investigation of cell physiological changes along design space development. PDA J Pharm Sci Technol 66(6):526-541. doi:10.5731/pdajpst.2012.00889

Salmond CV, Kroll RG, Booth IR (1984) The effect of food preservatives on $\mathrm{pH}$ homeostasis in Escherichia coli. Microbiology 130(11): 2845-2850. doi:10.1099/00221287-130-11-2845

Savageau MA (2011) Design of the lac gene circuit revisited. Math Biosci 231(1):19-38. doi:10.1016/j.mbs.2011.03.008

Saviola B, Seabold R, Schleif RF (1998) Arm-domain interactions in AraC. J Mol Biol 278(3):539-548. doi:10.1006/jmbi.1998.1712

Schlegel S, Löfblom J, Lee C, Hjelm A, Klepsch M, Strous M, Drew D, Slotboom DJ, J-Wd G (2012) Optimizing membrane protein overexpression in the Escherichia coli strain Lemo21(DE3). J Mol Biol 423(4):648-659. doi:10.1016/j.jmb.2012.07.019

Schlegel S, Rujas E, Ytterberg AJ, Zubarev RA, Luirink J, Gier J-W (2013) Optimizing heterologous protein production in the periplasm of $E$. coli by regulating gene expression levels. Microb Cell Factories 12(1):24. doi:10.1186/1475-2859-12-24

Schleif R (2000) Regulation of the L-arabinose operon of Escherichia coli. Trends Genet 16(12):559-565. doi:10.1016/s0168-9525(00)02153-3

Schleif R (2010) AraC protein, regulation of the l-arabinose operon in Escherichia coli, and the light switch mechanism of AraC action. FEMS Microbiol Rev 34(5):779-796. doi:10.1111/j.15746976.2010.00226.x

Siegele DA, JC H (1997) Gene expression from plasmids containing the araBAD promoter at subsaturating inducer concentrations represents mixed populations. Proc Natl Acad Sci U S A 94(15):8168-8172

Sommer B, Friehs K, Flaschel E (2010) Efficient production of extracellular proteins with Escherichia coli by means of optimized coexpression of bacteriocin release proteins. J Biotechnol 145(4): 350-358. doi:10.1016/j.jbiotec.2009.11.019

Stirling DA, Hulton CSJ, Waddell L, Park SF, Stewart GSAB, Booth IR, Higgins CF (1989) Molecular characterization of the proU loci of Salmonella typhimurium and Escherichia coli encoding osmoregulated glycine betaine transport systems. Mol Microbiol 3(8):1025-1038. doi:10.1111/j.1365-2958.1989.tb00253.x 
Striedner G, Cserjan-Puschmann M, Potschacher F, Bayer K (2003) Tuning the transcription rate of recombinant protein in strong Escherichia coli expression systems through repressor titration. Biotechnol Prog 19(5):1427-1432. doi:10.1021/bp034050u

Striedner G, Pfaffenzeller I, Markus L, Nemecek S, Grabherr R, Bayer K (2010) Plasmid-free T7-based Escherichia coli expression systems. Biotechnol Bioeng. doi:10.1002/bit.22598

Sutherland L, Cairney J, Elmore MJ, Booth IR, Higgins CF (1986) Osmotic regulation of transcription: induction of the proU betaine transport gene is dependent on accumulation of intracellular potassium. J Bacteriol 168(2):805-814

Tate CG, Muiry JA, Henderson PJ (1992) Mapping, cloning, expression, and sequencing of the rhaT gene, which encodes a novel L-rhamnose-H+ transport protein in Salmonella typhimurium and Escherichia coli. J Biol Chem 267(10):6923-6932

Textor S, Wendisch VF, De Graaf AA, Müller U, Linder MI, Linder D, Buckel W (1997) Propionate oxidation in Escherichia coli: evidence for operation of a methylcitrate cycle in bacteria. Arch Microbiol 168(5):428-436

Tobin JF, Schleif RF (1987) Positive regulation of the Escherichia coli Lrhamnose operon is mediated by the products of tandemly repeated regulatory genes. J Mol Biol 196(4):789-799. doi:10.1016/00222836(87)90405-0

Tobin JF, Schleif RF (1990a) Purification and properties of RhaR, the positive regulator of the L-rhamnose operons of Escherichia coli. J Mol Biol 211(1):75-89. doi:10.1016/0022-2836(90)90012-b

Tobin JF, Schleif RF (1990b) Transcription from the rha operon psr promoter. J Mol Biol 211(1):1-4. doi:10.1016/0022-2836(90)90003-5

Tsang AW, Horswill AR, Escalante-Semerena JC (1998) Studies of regulation of expression of the propionate (prpBCDE) operon provide insights into how Salmonella typhimurium LT2 integrates its 1,2propanediol and propionate catabolic pathways. J Bacteriol 180(24): $6511-6518$
Turner P, Holst O, Karlsson EN (2005) Optimized expression of soluble cyclomaltodextrinase of thermophilic origin in Escherichia coli by using a soluble fusion-tag and by tuning of inducer concentration. Protein Expr Purif 39(1):54-60. doi:10.1016/j.pep.2004.09.012

Vía P, Badía J, Baldomà L, Obradors N, Aguilar J (1996) Transcriptional regulation of the Escherichia coli rhaT gene. Microbiology 142(Pt 7): $1833-1840$

Wagner S, Klepsch MM, Schlegel S, Appel A, Draheim R, Tarry M, Högbom M, van Wijk KJ, Slotboom DJ, Persson JO, J-Wd G (2008) Tuning Escherichia coli for membrane protein overexpression. Proc Natl Acad Sci U S A 105(38):14371-14376. doi:10.1073/pnas.0804090105

Walawalkar YD, Phadke R, Noronha S, Patankar S, Pillai B (2013) Engineering whole-cell biosensors to evaluate the effect of osmotic conditions on bacteria. Ann Microbiol 63(4):1283-1290. doi:10.1007/s13213-012-0587-4

Weber A, Kogl SA, Jung K (2006) Time-dependent proteome alterations under osmotic stress during aerobic and anaerobic growth in Escherichia coli. J Bacteriol 188(20):7165-7175. doi:10.1128/jb.00508-06

Wickstrum JR, Santangelo TJ, Egan SM (2005) Cyclic AMP receptor protein and RhaR synergistically activate transcription from the L-rhamnoseresponsive rhaSR promoter in Escherichia coli. J Bacteriol 187(19): 6708-6718. doi:10.1128/jb.187.19.6708-6718.2005

Wickstrum JR, Skredenske JM, Balasubramaniam V, Jones K, Egan SM (2009) The AraC/XylS family activator RhaS negatively autoregulates rhaSR expression by preventing cyclic AMP receptor protein activation. J Bacteriol 192(1):225-232. doi: $10.1128 /$ jb.00829-08

Wilcox G (1974) The interaction of L-arabinose and D-fucose with AraC protein. J Biol Chem 249(21):6892-6894

Wilson T, Kashket E (1969) Isolation and properties of thiogalactoside transacetylase-negative mutants of Escherichia coli. Biochim Biophys Acta 173(3):501-508. doi:10.1016/0005-2736(69)90014-5 